\title{
Modeling and Multi-objective Optimization of a Packed Bed Reactor for Sulfur Dioxide Removal by Magnesium Oxide Using Non-dominated Sorting Genetic Algorithm II
}

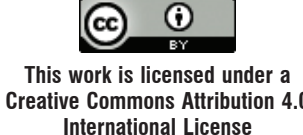

International License

\author{
A. Bakhshi Ani and H. Ale Ebrahim* \\ Department of Chemical Engineering, \\ Amirkabir University of Technology \\ (Tehran Polytechnic), Tehran, Iran
}

doi: https://doi.org/10.15255/CABEQ.2021.1913

Original scientific paper

Received: January 10, 2021

Accepted: June 30, 2021

Nowadays, protecting the environment is of utmost importance worldwide, and sulfur dioxide is one of the main pollutants in the atmosphere. This work proposes a new method for simultaneous $\mathrm{SO}_{2}$ removal by $\mathrm{MgO}$, and production of magnesium sulfate in a packed bed reactor for which breakthrough curves have been obtained. Furthermore, the effect of important operating parameters, including temperature, $\mathrm{SO}_{2}$ concentration, and gaseous flow rate was investigated. Experiments showed that increasing the temperature improved the breakthrough lifetime, but the increase in concentration and flow rate reduced the lifetime. The experimental results were predicted successfully by applying the Random Pore Model (RPM). Finally, the Non-dominated Sorting Genetic Algorithm II (NSGA II) that is a technique for multi-objective optimization, was employed to determine the best operating parameters for $\mathrm{SO}_{2}$ removal by magnesium oxide in the packed bed reactor.

Keywords

$\mathrm{SO}_{2}$ removal, magnesium oxide, packed bed reactor, random pore model, modeling and simulation, multi-objective optimization

\section{Introduction}

Nowadays, protecting the environment, and air pollutant removal processes are of great importance all over the world. Acid rain is one of the major environmental problems, and it can destroy the forests and aquatic animals. The most important factor resulting in the formation of acid rains is the presence of $\mathrm{SO}_{2}$ in the atmosphere. Sulfuric acid is produced as the result of $\mathrm{SO}_{2}$ and water vapor reaction, and falling to the ground with rain ${ }^{1,2}$.

The main sources of $\mathrm{SO}_{2}$ emission are metallurgical and coal-fired power plants (stationary units), and vehicles that consume high sulfur content fuel (mobile units) ${ }^{3}$. Many attempts have been made in order to reduce the sulfur dioxide emission to the atmosphere in the world. In many countries, the sulfur content of gasoline and gas oil should be below $10 \mathrm{ppm}$ (Euro 5 standard) ${ }^{4}$. These low-sulfur-content fuels are produced by deep hydrotreating processes in refineries ${ }^{5,6}$. Furthermore, in stationary units, flue gas desulfurization (FGD) processes are applied to adsorb or absorb sulfur dioxide and control the level of $\mathrm{SO}_{2}$ in the exhaust gases.

"Corresponding author: E-mail: alebrm@aut.ac.ir
FGD processes are categorized into the throwaway systems for low $\mathrm{SO}_{2}$ concentration, including coal-fired power plants, and regenerative systems for high $\mathrm{SO}_{2}$ concentration such as metallurgical units $^{3}$. The common adsorbents in throw-away systems are $\mathrm{CaO}, \mathrm{MgO}$, and $\mathrm{Fe}_{2} \mathrm{O}_{3}$.

The main reaction in throw-away FGD systems based on $\mathrm{MgO}$ is:

$$
\mathrm{MgO}+\mathrm{SO}_{2}+1 / 2 \mathrm{O}_{2} \rightarrow \mathrm{MgSO}_{4}
$$

On the other hand, magnesium sulfate is usually produced as a result of reaction between $\mathrm{MgO}$ and sulfuric acid. $\mathrm{MgSO}_{4}$ is mainly used in agriculture as a fertilizer. The increasing global demand for agricultural products has resulted in the increase of $\mathrm{MgSO}_{4}$ production. The other applications of magnesium sulfate are in medical, food preparation, and construction industries ${ }^{7}$.

The conventional methods of magnesium sulfate production are extraction of mineral kieserite, and $\mathrm{MgO}$ reaction with $\mathrm{H}_{2} \mathrm{SO}_{4}$. In the first method, kieserite is dissolved in water and $\mathrm{MgSO}_{4}$ product is obtained by crystallization process. In the second method, $\mathrm{MgO}$ (from magnesite calcination) is reacted with $\mathrm{H}_{2} \mathrm{SO}_{4}$ producing $\mathrm{MgSO}_{4}$ and then crystallization is used to increase the purity of the final product $^{8}$. 
The conducted research on the ability of $\mathrm{MgO}$ to capture $\mathrm{SO}_{2}$ in FGD systems are much fewer, compared to the calcium oxide. Jae et al. studied $\mathrm{MgO}$-based sorbents in a fixed bed reactor to adsorb sulfur dioxide'. They prepared regenerable sorbents by adding cerium and iron as additives into the MgO-based sorbents. Based on their results, the efficiency of the sorbents and the rate of reaction had improved by using these additives.

Zhang et al. adsorbed $\mathrm{SO}_{2}$ by using natural magnesite ${ }^{10}$. They declared that calcination temperature is a key parameter and that it affects adsorption capacity of sorbents. The adsorption capacity was reported to be $140.7 \mathrm{mg} \mathrm{g}^{-1}$.

Prezepiorski et al. studied the adsorption of $\mathrm{SO}_{2}$ from air by using $\mathrm{MgO} /$ carbon sorbents $^{11}$. Furthermore, they considered the effect of operating parameters such as temperature, porosity, and humidity, and analyzed the adsorption mechanism.

Zermeno et al. used natural magnesite in packed bed reactor and obtained the experimental breakthrough profiles of the reactor ${ }^{12}$. They announced that natural magnesite had a good adsorption capacity. They also declared that natural magnesite could be considered as a good alternative for $\mathrm{CaO}$.

Lee et al. studied the removal of sulfur dioxide by magnesium oxide ${ }^{13}$. They improved the adsorption capacity of sorbents by adding titanium dioxide. Their sorbents were prepared by co-precipitation method. They improved the adsorption capacity of the sorbent by adding $\mathrm{TiO}_{2}$ from $38 \mathrm{~g}$ sulfur $\mathrm{g}^{-1}$ to $44 \mathrm{~g}$ sulfur $\mathrm{g}^{-1}$.

Based on the analysis carried out by Magnabosco, $\mathrm{MgO}$ can be used as a suitable adsorbent for $\mathrm{SO}_{2}$ removal in the regenerator of $\mathrm{FCC}$ unit $^{14}$.

Li et al. found that the operating cost of FGD process based on $\mathrm{MgO}$ is lower than the FGD process based on $\mathrm{CaO}$ or $\mathrm{CaCO}_{3}{ }^{15}$.

Yi et al. evaluated $\mathrm{MgO}$ for simultaneous adsorption of $\mathrm{SO}_{2}$ and $\mathrm{NO}_{\mathrm{x}}$ from coal-fired power plant flue gas ${ }^{16}$. The performance of different morphologies of $\mathrm{MgO}$ was also considered in the study.

Liato et al. examined $\mathrm{MgO}$ in the wet FGD process for $\mathrm{SO}_{2}$ removal ${ }^{17}$. They announced that $\mathrm{MgO}$ showed a high capacity for adsorbing $\mathrm{SO}_{2}$.

Zou et al. used $\mathrm{MgO}$ for simultaneous removal of $\mathrm{SO}_{2}$ and $\mathrm{NO}_{x}$ with oxidation of ozone ${ }^{18}$. Furthermore, the effect of $\mathrm{O}_{3} / \mathrm{NO}$ molar ratio, oxidation temperature and other operating parameters were considered. They reported that increasing $\mathrm{SO}_{2}$ concentration had a negative effect on $\mathrm{NO}_{\mathrm{x}}$ removal efficiency.

Wang et al. studied oxidation of $\mathrm{SO}_{2}$ to sulfate on surface of $\mathrm{MgO}$ by diffuse reflectance infrared Fourier transform spectroscopy ${ }^{19}$. They revealed that the product of $\mathrm{MgO}+\mathrm{SO}_{2}$ reaction was sulfite, bisulfite, and sulfate.

Zhao and Zou tested micro-sized MgO slurry and $\mathrm{MgO}$ nanofluids slurry in wet desulfurization process $^{20}$. They found that the efficiency of $\mathrm{MgO}$ nanofluids was better than that of micro-sized $\mathrm{MgO}$ slurry.

Many attempts have been made to model gas-solid reactions. We were able to predict the performance of real systems by efficient application of modeling and simulation ${ }^{21}$. Furthermore, modeling and simulation along with the application of mathematical tools such as genetic algorithm, can lead to the discovery of optimum operating parameters of the various processes.

Dry FGD process is an important type of non-catalytic gas-solid reactions that $\mathrm{SO}_{2}$ adsorbed by adsorbents like $\mathrm{MgO}, \mathrm{CaO}$, and $\mathrm{CuO}$. Kinetic study of these reactions is an appropriate tool for improvement of FGD process through design and optimization of the related reactors. For this reason, various models including shrinking core model, volume reaction model, grain model, modified grain model, nucleation model, single pore model, and random pore model (RPM) are developed. RPM and modified grain model are able to consider incomplete conversion due to volume increase of the pellet during the reaction. Complicated RPM theory assumes that the reaction occurs on the inner surfaces of cylindrical pores of the sorbent in the series of holes that have a pore size distribution (PSD).

Bahrami et al. used RPM to simulate $\mathrm{SO}_{2}$ removal by $\mathrm{CuO}$ as a regenerative process ${ }^{22}$. The experimental operating parameters in their work included temperature $\left(400-600^{\circ} \mathrm{C}\right)$ and sulfur dioxide concentration (1250-5000 ppm). They compared the experimental data with the values predicted by RPM. They declared that RPM could predict the experimental conversion-time data with a high degree of accuracy.

Moshiri et al. adsorbed $\mathrm{SO}_{2}$ in a packed bed reactor by using $\mathrm{CaO}^{23}$. Their experimental breakthrough curves were modeled by RPM. They found that RPM could accurately predict the experimental data.

Betancur et al. studied gasification process by thermogravimetry and modeled the experimental data by grain model, RPM and hybrid modification $\mathrm{RPM}^{24}$. They concluded that RPM and hybrid modified RPM were the most precise models.

Lopez et al. considered $\mathrm{CaO}$ reaction with carbon dioxide, and evaluated the effect of inert support ${ }^{25}$. They applied RPM to calculate the kinetic parameters.

Montagnaro et al. modeled the $\mathrm{CaO}+\mathrm{SO}_{2}$ reaction by $\mathrm{RPM}^{26}$. They then compared the experimen- 
tal results with the RPM. They announced that the model could correlate the experimental data.

Removal of sulfur dioxide with $\mathrm{CuO}$ in a thermogravimeter was examined by $\mathrm{Yu}$ et al. ${ }^{27}$ The experimental results were predicted by volume reaction model, grain size model, RPM and pore-blocking model.

Nouri et al. evaluated the adsorption of $\mathrm{CO}_{2}$ by lime in a packed bed reactor and obtained the experimental breakthrough curves ${ }^{28}$. Furthermore, the acid washing technique was used in their study to improve the adsorption capacity of lime. Finally, they predicted the experimental breakthrough curves with RPM.

In our previous studies, the kinetic parameters of $\mathrm{MgO}+\mathrm{SO}_{2}$ reaction were calculated by RPM and the adsorption capacity of $\mathrm{MgO}$ was improved by acid washing method, and the experimental conversion-time and breakthrough curves were compared with the natural sample ${ }^{29,30}$. Finally, RPM was applied to model the experimental data.

Process optimization has become an interesting area of research during recent years, and as a result, attempts have been made to find the best operating conditions for different chemical processes. Optimization will maximize the process performance and minimize the operating costs. Furthermore, the optimization results can be used as the optimum conditions for large-scale industrial units operations ${ }^{31,32}$.

Wu et al. applied multi-objective optimization for hydrotreating process ${ }^{33}$. They optimized the process to minimize the operating cost and $\mathrm{SO}_{2}$ emission to the environment. They found that the operating cost and emission of sulfur dioxide would be reduced in high temperatures and low pressures.

Zhou et al. considered multi-objective optimization of $\mathrm{SO}_{2}$ removal by activated coke and found the best sorbent preparation parameters ${ }^{34}$. They found that the best operating conditions were at $924{ }^{\circ} \mathrm{C}$, oxygen concentration $5.9 \%$, and vapor concentration $20 \%$.

Bayon et al. optimized the operation of a thermal power plant to minimize $\mathrm{SO}_{2}$ and $\mathrm{NO}_{x}$ emissions to the environment ${ }^{35}$.

Bakhshi Ani et al. simulated a trickle-bed hydrotreating reactor and used multi-objective optimization to find the best operating conditions of the process $^{5}$. They also considered the effect of operating parameters such as temperature, pressure, LHSV, and $\mathrm{H}_{2} /$ oil.

Liu et al. simulated desulfurization tower by CFD tool and optimized the related operating parameters ${ }^{36}$. They found that CFD could accurately predict the experimental data.

To the best of our knowledge, no previous research has been conducted on RPM for $\mathrm{MgO}+\mathrm{SO}_{2}$ packed bed reaction, and a few attempts have been made to investigate the behavior of packed bed reactor for adsorption of $\mathrm{SO}_{2}$ by $\mathrm{MgO}$. Furthermore, no one has reported the best operating conditions for $\mathrm{SO}_{2}$ removal in packed bed reactor so far. Therefore, in the present study, the tests were performed to obtain the experimental breakthrough curves of natural $\mathrm{MgO}$ in the packed bed reactor. The effects of important operating parameters, such as $\mathrm{SO}_{2}$ concentration, temperature, and gaseous flow rate on lifetime of the breakthrough curves were investigated experimentally. Then, RPM as a comprehensive and precise model that considers the structural changes of sorbents was applied to simulate the experimental results. The possibility of magnesium sulfate production as a useful by product in the $\mathrm{SO}_{2}$ removal process by $\mathrm{MgO}$ is also considered.

Finally, NSGA II as a technique for multi-objective optimization was employed to determine the best operating parameters for $\mathrm{SO}_{2}$ removal by magnesium oxide in the packed bed reactor.

\section{Materials and methods}

Natural magnesium carbonate/oxide was supplied from the Nehbandan mine (Iran), in the form of spherical particles of about $6 \mathrm{~mm}$ in diameter. The composition of the mineral sample is presented in Table 1. The data in this table was obtained from the XRF analysis results. Highly pure $\mathrm{SO}_{2}(99.95 \%)$ and zero air (mixture of pure oxygen and nitrogen) were the gases used in this research.

The experimental setup included tubular reactor (310 stainless steel, $1.5 \mathrm{~cm}$ inner diameter, and 6 $\mathrm{cm}$ height), K-type thermocouple, vertical furnace, two MFCs (mass flow controller), and online mass spectrometer (MS). The schematic diagram of the apparatus is presented in Fig. 1.

The calcination process was applied to prepare a highly porous $\mathrm{MgO}$ from magnesium carbonate/ oxide directly in the packed bed reactor as part of the experimental setup. In this process, the sample was heated to the operating reaction temperature $\left(500-600{ }^{\circ} \mathrm{C}\right.$ ) for about $30 \mathrm{~min}$ under zero-air stream. The porosity of the sample increased due to the release of $\mathrm{H}_{2} \mathrm{O}$ and $\mathrm{CO}_{2}$ molecules from mineral magnesium carbonate/oxide.

After the calcination process, $\mathrm{SO}_{2}$ was mixed in zero-air in the predefined concentration, and it was injected to the reactor to start the adsorption/ reaction. MS continuously monitored outlet gases from the reactor. The experimental breakthrough curves were obtained from MS results. Table 2 shows the operating conditions of the experiments. 
Table $1-X R F$ analysis of the natural magnesium carbonatel oxide from Nehbandan mine

\begin{tabular}{cc}
\hline Component & wt $\%$ \\
\hline $\mathrm{Na}_{2} \mathrm{O}$ & 0.04 \\
$\mathrm{MgO}$ & 92.94 \\
$\mathrm{SiO}_{2}$ & 3.52 \\
$\mathrm{P}_{2} \mathrm{O}_{5}$ & 0.03 \\
$\mathrm{SO}_{3}$ & 0.09 \\
$\mathrm{Cl}$ & 0.05 \\
$\mathrm{CaO}$ & 1.64 \\
$\mathrm{MnO}$ & 0.23 \\
$\mathrm{Fe}_{2} \mathrm{O}_{3}$ & 1.07 \\
$\mathrm{NiO}$ & 0.36 \\
\hline
\end{tabular}

Table 2 -Operating conditions of the packed bed reactor

\begin{tabular}{lc}
\hline \multicolumn{1}{c}{ Property } & value \\
\hline Packed bed length $(\mathrm{cm})$ & 6 \\
Zero-air flow $\left(\mathrm{m}^{3} \mathrm{~s}^{-1}\right)$ & $1.67 \cdot 10^{-6}-3.34 \cdot 10^{-6}$ \\
$\mathrm{SO}_{2}$ concentration $(\mathrm{vol} . \%)$ & $1-2$ \\
Temperature $\left({ }^{\circ} \mathrm{C}\right)$ & $500-600$ \\
\hline
\end{tabular}

\section{Packed bed reactor modeling}

RPM as a comprehensive and real model was employed in this study to simulate the packed bed reactor behavior and predict the breakthrough curves. This model was developed by Bhatia and Perlmutter and its main assumptions are ${ }^{37-39}$ :

- Pseudo-steady state approximation;

- Negligible bulk flow effect;

- Isothermal condition for system;

- Irreversible and first order reaction.

The RPM governing equations with the initial and boundary conditions are ${ }^{22}$ :

$$
\frac{1}{y^{2}} \frac{\partial}{\partial y}\left(\delta y^{2} \frac{\partial a}{\partial y}\right)=\frac{\phi^{2} a b \sqrt{1-\psi \ln b}}{1+\frac{\beta Z}{\psi}[\sqrt{1-\psi \ln b}-1]}
$$

$$
\frac{\partial b}{\partial \theta}=-\frac{a b \sqrt{1-\psi \ln b}}{1+\frac{\beta Z}{\psi}[\sqrt{1-\psi \ln b}-1]}
$$

$$
\theta=0: \quad b=1
$$

$$
y=0: \quad \frac{\partial a}{\partial y}=0
$$

$$
y=1: \quad \frac{\partial a}{\partial y}=\frac{S h}{\delta}(1-a)
$$

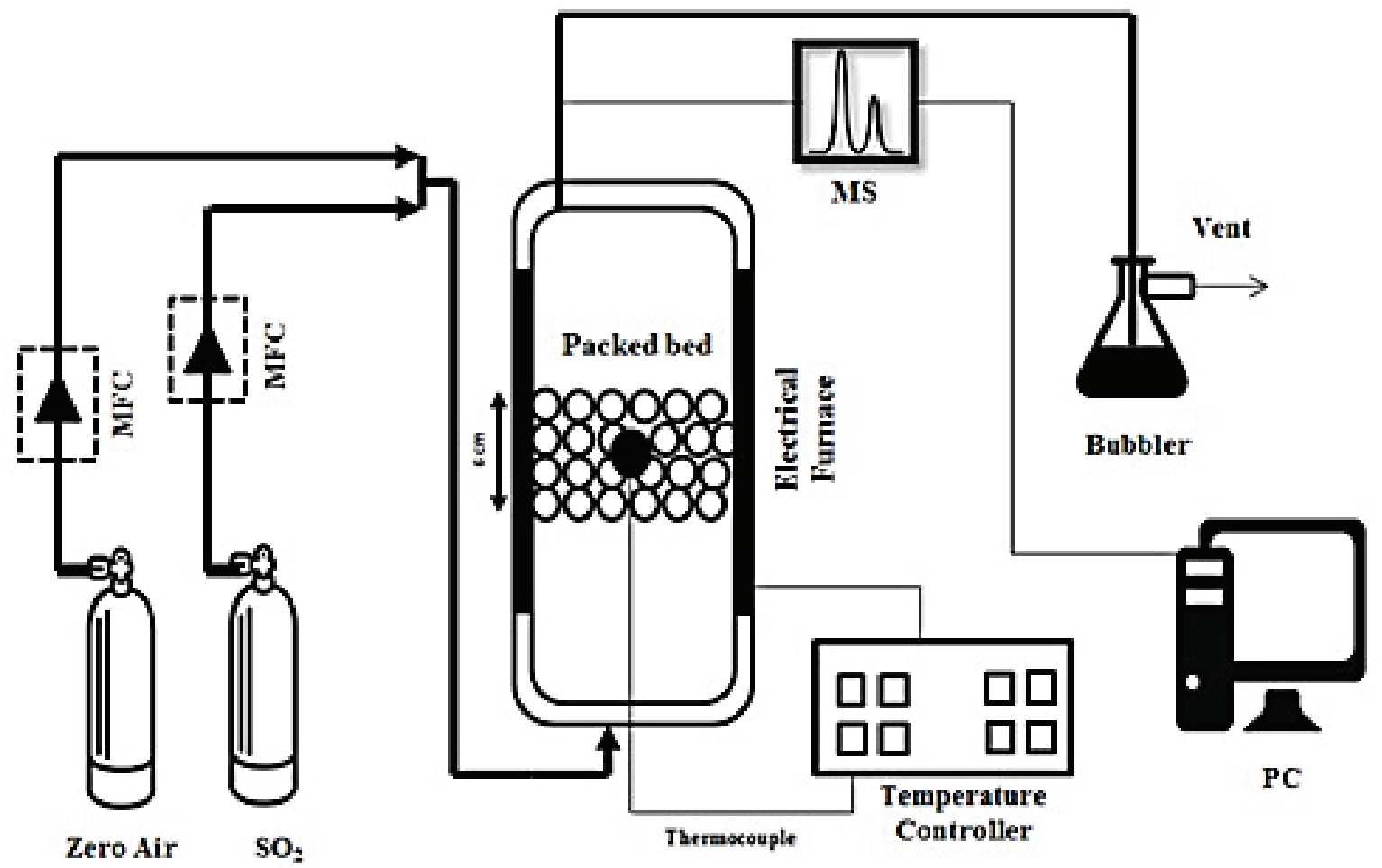

Fig. 1 -Packed bed reactor setup with outlet gas analysis by mass spectrometer 
In equation (1), $\psi$ is the main RPM parameter obtained from the whole PSD of the calcined sample. The packed bed reactor differential equations were derived from the mass balance as follows ${ }^{37}$ :

For bulk gas in the reactor:

$$
\begin{gathered}
\frac{\partial^{2} w}{\partial \zeta^{2}}-P e \frac{\partial w}{\partial \zeta}=\alpha\left(w-\zeta_{y=1}\right) \\
\zeta=0: \quad w=1 \\
\zeta=\Lambda: \quad \frac{\partial w}{\partial \zeta}=0
\end{gathered}
$$

For the reactant gas in the pellet:

$$
\begin{gathered}
\frac{1}{y^{2}} \frac{\partial}{\partial y}\left(y^{2} \frac{\partial \zeta}{\partial y}\right)=\phi^{2} f(x) \zeta \\
y=0: \quad \frac{\partial \zeta}{\partial y}=0
\end{gathered}
$$

The $f(x)$ in equation (10) is inserted from the right-hand side of equation (3).

For the solid reactant:

$$
\begin{gathered}
\frac{\partial X}{\partial \tau}=f(x) \zeta \\
\tau=0: \quad X=0
\end{gathered}
$$

The variables of the packed bed reactor are expressed as follows:

$$
\begin{gathered}
\zeta=\frac{x}{R} \\
y=\frac{r_{p}}{R} \\
\zeta=\frac{C_{A}}{C_{A b 0}} \\
w=\frac{C_{A b}}{C_{A b 0}} \\
\tau=v_{B} \frac{k C_{A b 0} t}{C_{B 0}} \\
\Lambda=\frac{L}{R}
\end{gathered}
$$

The parameters of the system are presented as follows:

$$
P e=\frac{u R}{D_{L}}
$$

$$
\begin{gathered}
\alpha=\frac{(1-\varepsilon)}{\varepsilon} \frac{3 k_{m} R}{D_{L}} \\
\phi^{2}=\frac{v_{A} k R^{2}}{D_{e}} \\
B i_{m}=\frac{k_{m} R}{D_{e}}
\end{gathered}
$$

The energy consumption in calcination process to reach and maintain the reactor at desired temperature can be calculated from the following equation based on the energy balance:

$$
\begin{aligned}
Q= & m_{a d} C_{p, a d}\left(T_{c a l}-T_{0}\right)+ \\
& +m_{r} C_{p, r}\left(T_{c a l}-T_{0}\right)+h A_{r}\left(T_{c a l}-T_{0}\right) \cdot t_{c a l}
\end{aligned}
$$

The solution method for solving nonlinear RPM and packed bed reactor partial differential equations was developed in MATLAB ${ }^{\circledR}$ based on the finite element method. The details about the solution method has been already described in our previous study ${ }^{23}$. The explanation for all of the symbols that have been used in Eq. (2) to (24) are given in the nomenclature part.

\section{Optimization}

One of the well-known optimization tools is genetic algorithm (GA) that is based on Darwinian evolution. The main operators of GAs are crossover, recombination, mutation, and selection ${ }^{40}$. The first step in GA is the random selection of a population from the parent chromosomes. The evolution of selected population to the better chromosomes is applied by GA main operators. The chromosomes for recombination are chosen in the selection stage. The new offspring chromosomes are generated in recombination stage from two parents after finishing the selection stage. Then, the children enter the mutation stage. In the mutation stage, new features are added to the population by creating new chromosomes from one child ${ }^{41}$.

Srinivas and Deb introduced the Non-dominated Sorting Genetic Algorithm (NSGA) in 1995. In 2000, Deb proposed NSGA II to solve some difficulties of NSGA ${ }^{42}$. NSGA II utilizes the elite strategy to sort parents' and children populations. The diversity of solutions was enhanced by using crowded comparison operator in NSGA II. In this study, the evaluation tool in NSGA II was the packed bed reactor model and the energy consumption equation. The calculation work flow chart of NSGA II is presented in Fig. 2. 


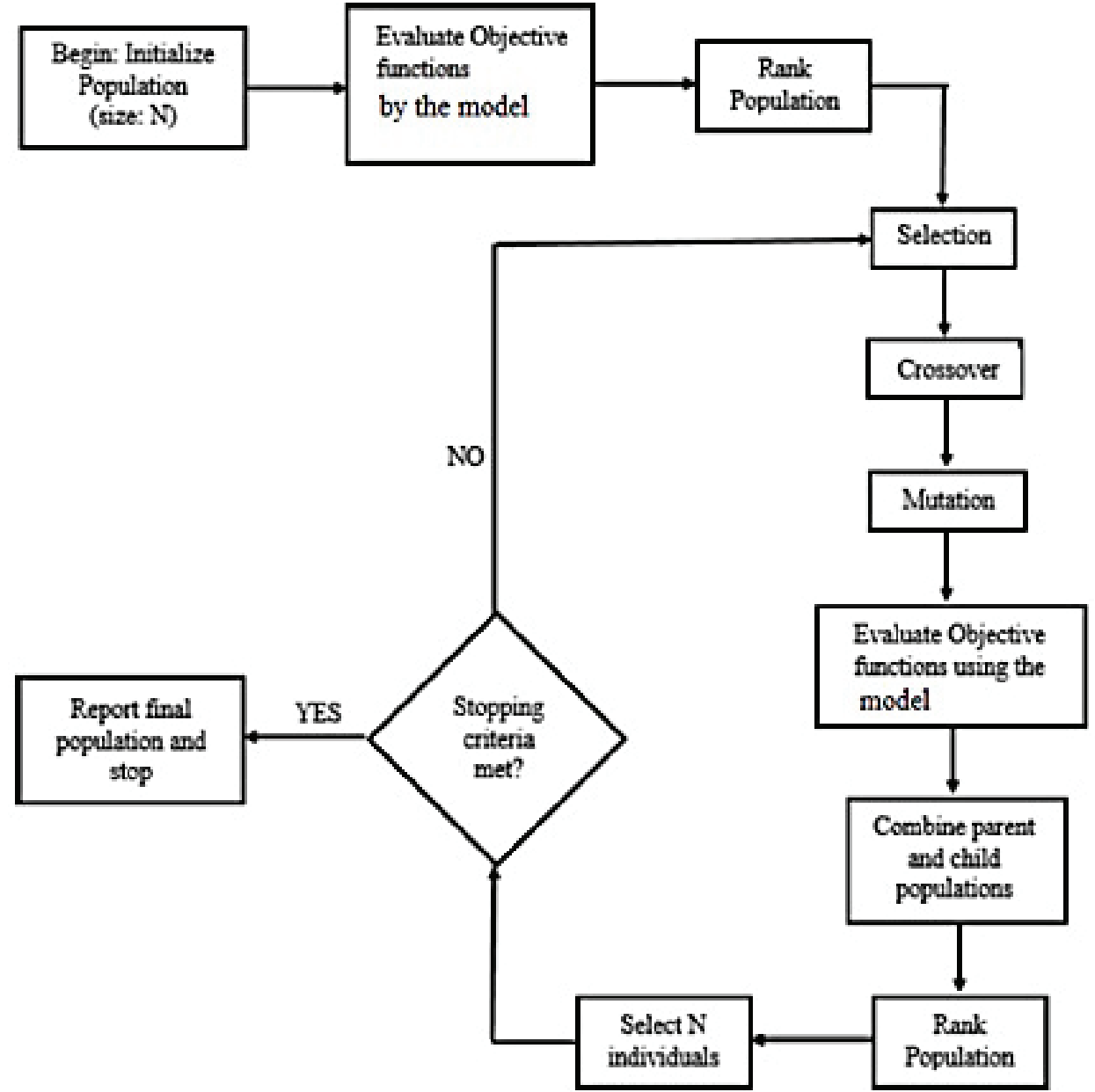

Fig. 2 - Calculation work flow chart of NSGA II

\section{Results and discussion}

\section{Model validation}

As mentioned, packed bed reactors with suitable sorbents can be used in air pollutants removal processes, such as FGD ( $\mathrm{SO}_{2}$ elimination), and $\mathrm{CO}_{2}$ concentrating from flue gases. In these reactors, evolution of the breakthrough curve (measuring pollutant outlet concentration versus time) is essential, since breakthrough curve determines effective lifetime of a packed bed reactor in the aforementioned environmental engineering processes. Consequently, mathematical modeling for accurate prediction of breakthrough curve of a packed bed reactor is of great importance.

The experimental breakthrough curve of exit sulfur dioxide from the natural $\mathrm{MgO}$ reaction in the packed bed at $600{ }^{\circ} \mathrm{C}, 1$ vol. $\% \mathrm{SO}_{2}$ concentration, and $1.67 \cdot 10^{-6} \mathrm{~m}^{3} \mathrm{~s}^{-1}\left(100 \mathrm{cc} \mathrm{min}^{-1}\right)$ zero-air flow (base case) is presented in Fig. 3. Based on the results, the breakthrough time is about $210 \mathrm{~min}$.

The breakthrough curve of natural magnesium oxide in the packed bed was predicted by the RPM.
Table 3 -Required parameters for RPM

\begin{tabular}{|c|c|c|}
\hline \multirow{2}{*}{ Parameter } & \multicolumn{2}{|c|}{ Value } \\
\hline & $500{ }^{\circ} \mathrm{C}$ & $600^{\circ} \mathrm{C}$ \\
\hline$D_{L}\left(\mathrm{~m}^{2} \mathrm{~s}^{-1}\right)$ & $2.2 \cdot 10^{-6}$ & $2.7 \cdot 10^{-6}$ \\
\hline $\bar{r}(\mathrm{~m})$ & \multicolumn{2}{|c|}{$2.66 \cdot 10^{-7}$} \\
\hline$\varepsilon_{0}$ & \multicolumn{2}{|c|}{0.69} \\
\hline$S_{0}\left(\mathrm{~cm}^{-1}\right)$ & \multicolumn{2}{|c|}{$6.32 \cdot 10^{6}$} \\
\hline$L_{0}\left(\mathrm{~cm}^{-2}\right)$ & \multicolumn{2}{|c|}{$6.1 \cdot 10^{12}$} \\
\hline$\psi$ & \multicolumn{2}{|c|}{0.58} \\
\hline$k_{\mathrm{s}}$ & \multicolumn{2}{|c|}{$2.38 \cdot 10^{-3} \exp \left(\frac{-38629.33}{R T}\right)$} \\
\hline$D_{\mathrm{p}}$ & \multicolumn{2}{|c|}{$3.28 \cdot 10^{-14} \exp \left(\frac{-68474.1}{R T}\right)$} \\
\hline
\end{tabular}

The required parameters to predict the curve by RPM are represented in Table 3 from our previous studies $^{29,30}$. The RPM main parameter $(\psi)$ was calculated from the whole PSD (micro, meso, and macro) of the calcined magnesium oxide pellets. 


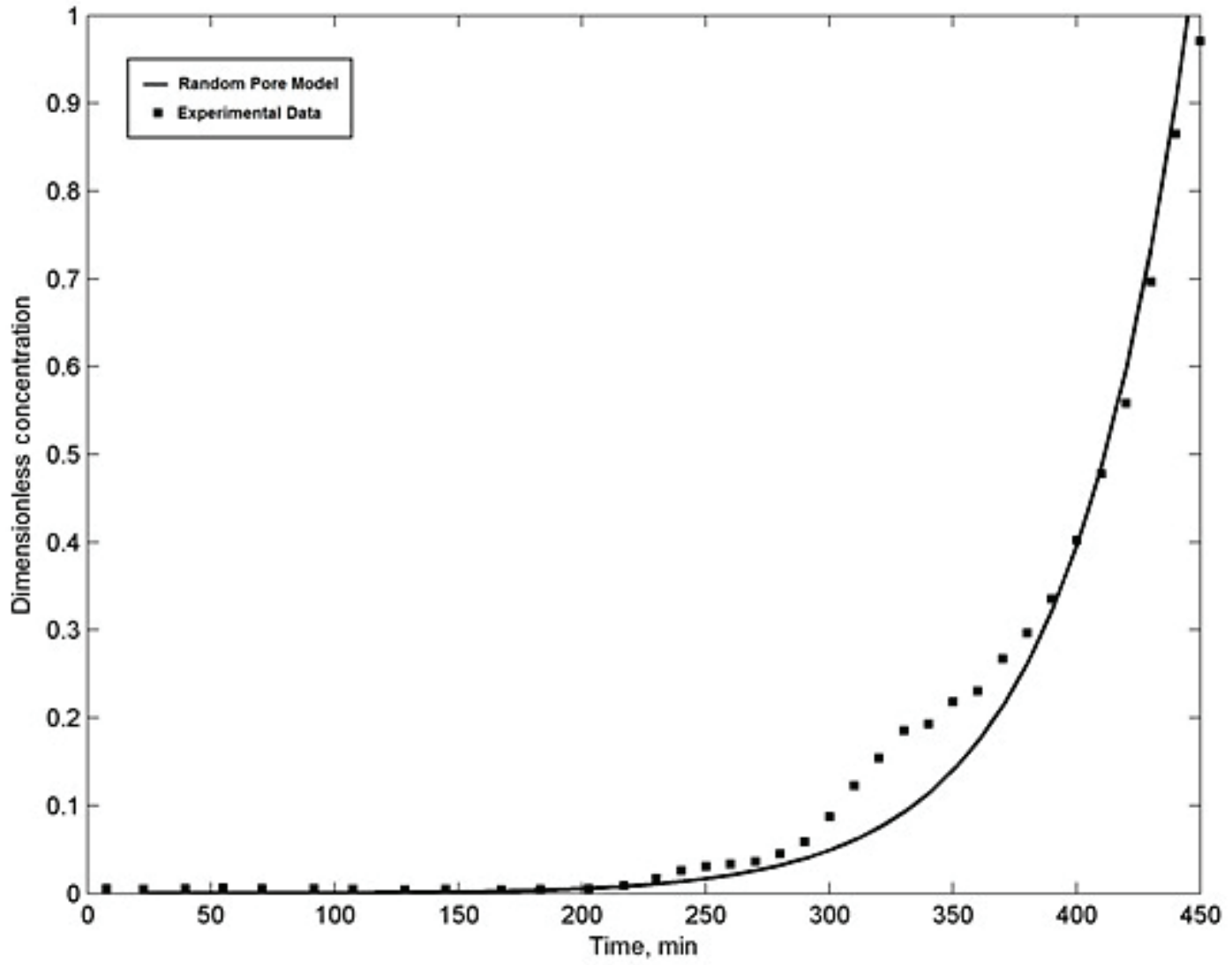

Fig. 3 - Comparison between random pore model predictions and experimental $\mathrm{SO}_{2}$ breakthrough curves from $\mathrm{MgO}$ packed bed reactor at base case $\left(600{ }^{\circ} \mathrm{C}, 1 \mathrm{vol} \% \mathrm{SO}\right.$ concentration, and $1.67 \cdot 10^{-6} \mathrm{~m}^{3} \mathrm{~s}^{-1}\left(100 \mathrm{cc} \mathrm{min}{ }^{-1}\right)$ zero-air flow rate)

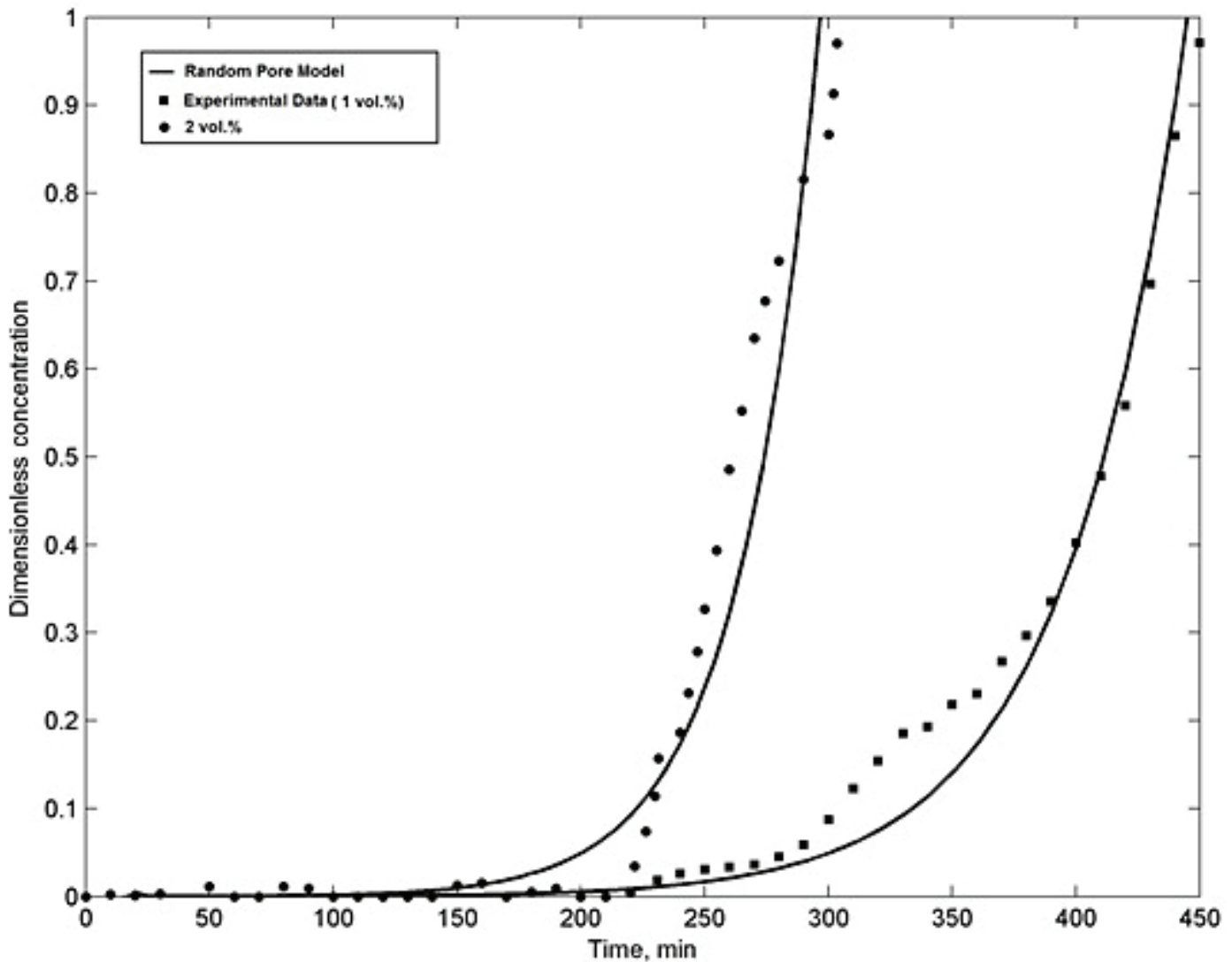

Fig. 4 - Comparison between random pore model predictions and experimental $\mathrm{SO}_{2}$ breakthrough curves from $\mathrm{MgO}$ packed bed reactor

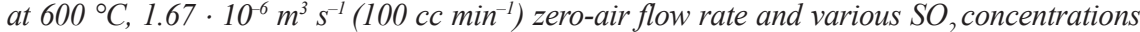




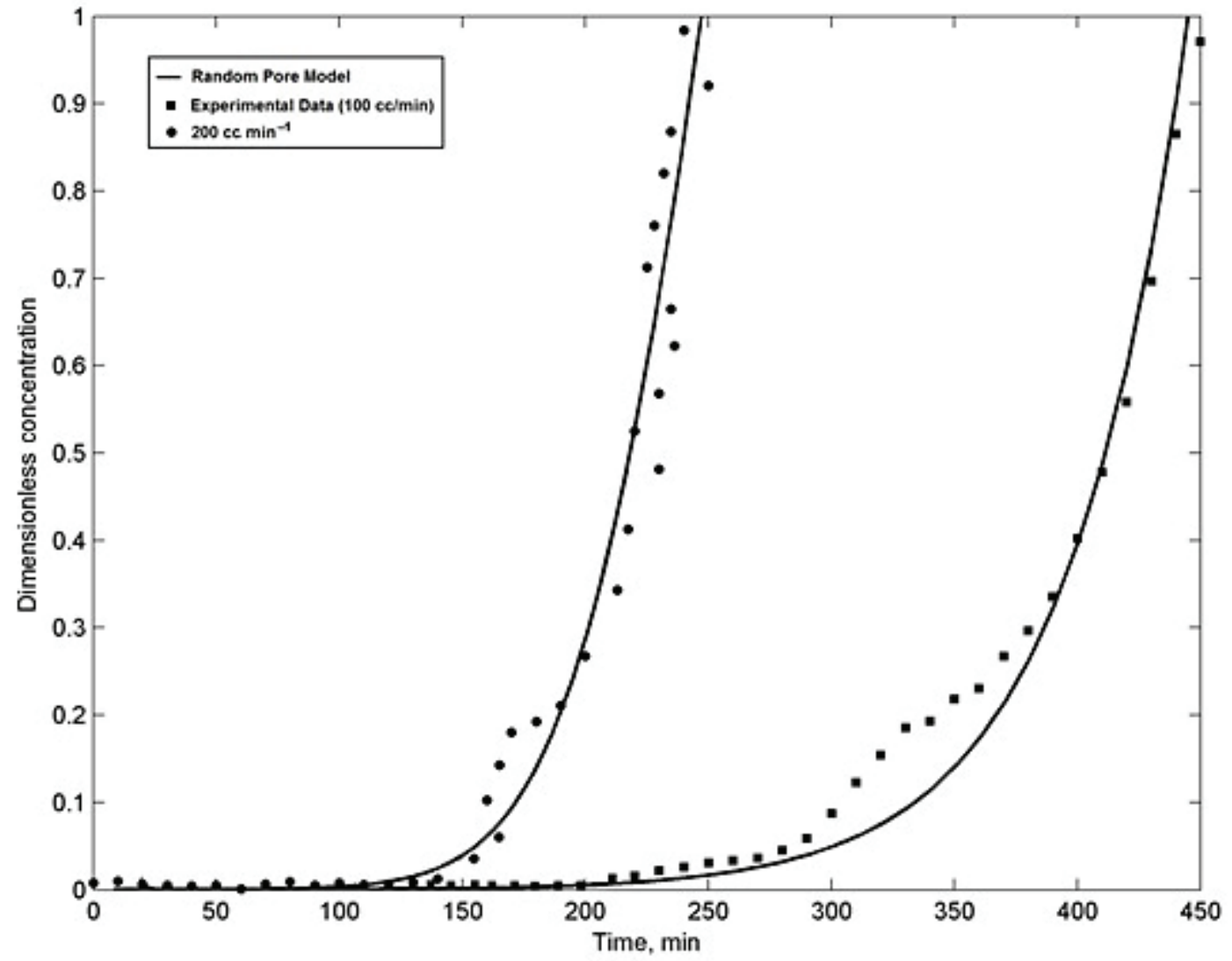

Fig. 5 - Comparison between random pore model predictions and experimental $\mathrm{SO}_{2}$ breakthrough curves from $\mathrm{MgO}$ packed bed reactor at $600{ }^{\circ} \mathrm{C}, 1$ vol. $\% \mathrm{SO}_{2}$ concentration, and various zero-air flow rates

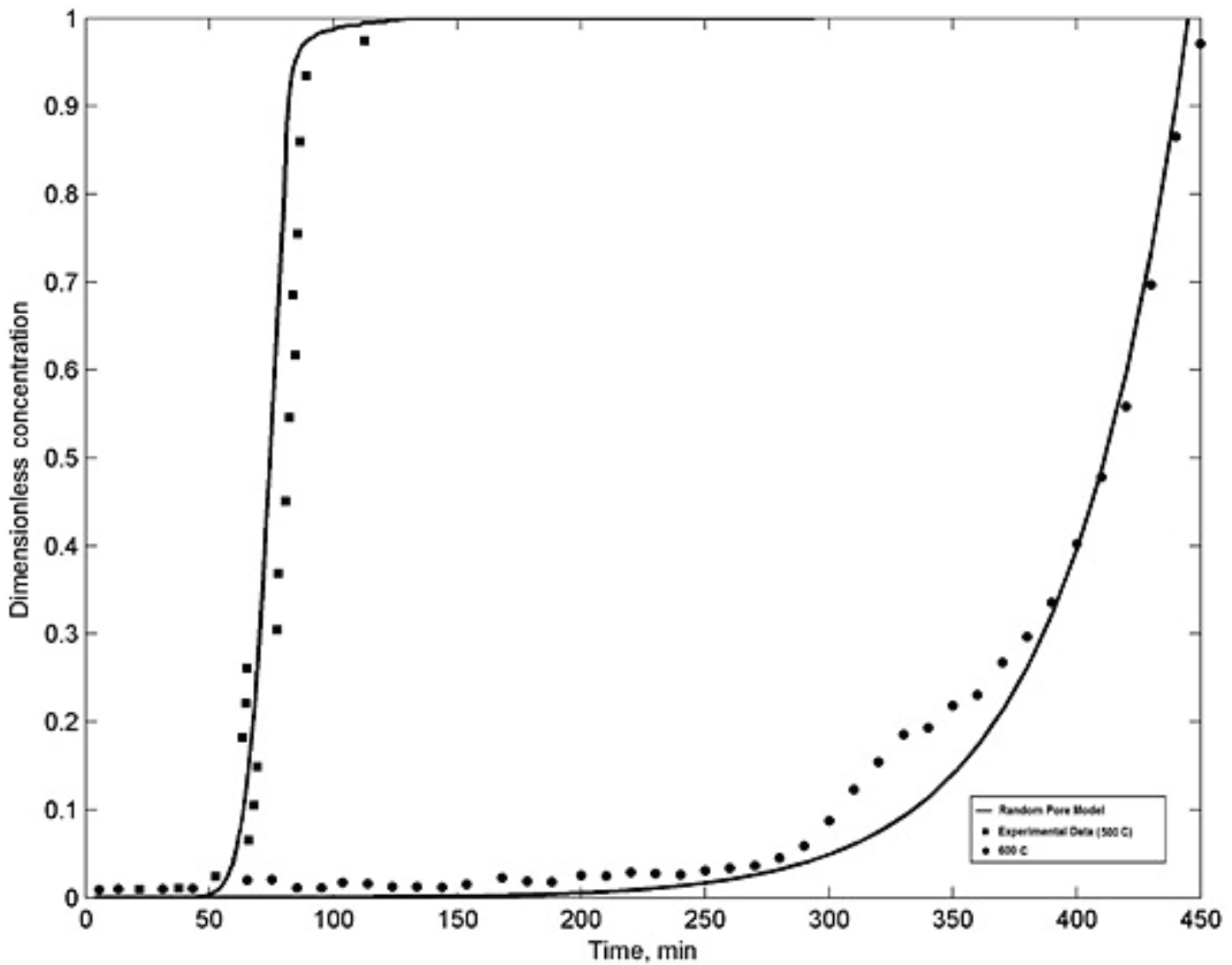

Fig. 6 - Comparison between random pore model predictions and experimental $\mathrm{SO}_{2}$ breakthrough curves from $\mathrm{MgO}$ packed bed reactor at $1 \mathrm{vol} \% \mathrm{SO}$ concentration, $1.67 \cdot 10^{-6} \mathrm{~m}^{3} \mathrm{~s}^{-1}\left(100 \mathrm{cc} \mathrm{min}{ }^{-1}\right)$ zero-air flow rate and various temperatures 
The axial dispersion $\left(D_{L}\right)$ is the sole fitting parameter obtained from the shape of the experimental breakthrough curve. Fig. 3 demonstrates good agreement between the model curve and experimental data.

Fig. 4 illustrates the effect of $\mathrm{SO}_{2}$ concentration on the breakthrough time. The breakthrough time was reduced from 210 min to 160 min by increasing $\mathrm{SO}_{2}$ concentration from 1 vol.\% (base case) to 2 vol. $\%$ due to the input of more sulfur dioxide reactant (versus the base case) to the packed bed reactor.

The effect of zero-air flow rate on the breakthrough time is presented in Fig. 5. The breakthrough time decreased from 210 to $120 \mathrm{~min}$ by increasing zero-air flow rate from $1.67 \cdot 10^{-6} \mathrm{~m}^{3} \mathrm{~s}^{-1}$ (100 cc $\mathrm{min}^{-1}$, base case) to $3.34 \cdot 10^{-6} \mathrm{~m}^{3} \mathrm{~s}^{-1}$ (200 cc $\left.\min ^{-1}\right)$. This effect was due to reduction in gaseous flow residence time versus the base case condition ${ }^{43}$.

The effect of temperature on the breakthrough time of packed bed reactor is shown in Fig. 6. The breakthrough time was reduced from 210 to $50 \mathrm{~min}$ by decreasing the temperature from $600{ }^{\circ} \mathrm{C}$ (base case operating temperature) to $500{ }^{\circ} \mathrm{C}$. The reduction was the consequence of the decreased reaction rate. Similar behavior was also observed in the adsorption of $\mathrm{SO}_{2}$ with $\mathrm{CuO}$ in the packed bed reactor $^{22}$.

In Figs. 4 to 6 , the values predicted by the model are in relatively good agreement with the experimental breakthrough curve data.

\section{Magnesium sulfate production}

During the process of $\mathrm{SO}_{2}$ removal by $\mathrm{MgO}$, magnesium sulfate is also produced. Magnesium sulfate is widely used in agriculture and various industries. Simultaneous $\mathrm{MgSO}_{4}$ production as a valuable compound is an advantage of using $\mathrm{MgO}$ as adsorbent for $\mathrm{SO}_{2}$ removal. The combination of $\mathrm{SO}_{2}$ removal system with $\mathrm{MgSO}_{4}$ production unit can improve the economic feasibility of FGD unit.

Fig. 7 shows the XRD analysis of the sample, before and after reaction with $\mathrm{SO}_{2}$ in the packed bed reactor. The analysis shows that $\mathrm{MgSO}_{4}$ was produced as a result of $\mathrm{MgO}+\mathrm{SO}_{2}+1 / 2 \mathrm{O}_{2}$ FGD reaction. The average overall conversion of $\mathrm{MgSO}_{4}$ in the packed bed reactor system from RPM is presented in Fig. 8 for the base case. During the early stages of the process, the kinetics and pore diffusion controlled the reaction. Then, the product layer diffusion controlled the overall reaction, and consequently, the conversion rate decreased. In this process, the produced $\mathrm{MgSO}_{4}$ is soluble in water and can be easily separated from the unreacted $\mathrm{MgO}$.

\section{Comparison of $\mathrm{MgO}$ FGD performance with other sorbents}

In this section, the performance of $\mathrm{MgO}$ in $\mathrm{SO}_{2}$ removal process was compared with other common sorbents, such as $\mathrm{CuO}, \mathrm{CaO}$, and $\mathrm{Fe}_{2} \mathrm{O}_{3}$ for sulfur dioxide abatement according to the available literature data in the field. The basis of this comparison were breakthrough time and the rate constant values. It is worth mentioning that both parameters might not be reported in the literature for all of these sorbents.

A complete kinetics study of $\mathrm{SO}_{2}+\mathrm{CuO}$ reaction was carried out in a thermogravimeter by Bahrami et al. ${ }^{22}$ They asserted that the rate constant for $\mathrm{CuO}$ at $500{ }^{\circ} \mathrm{C}$ was $4.37 \cdot 10^{-8} \mathrm{~m} \mathrm{~s}^{-1}$, while this value for $\mathrm{MgO}$ was $6.01 \cdot 10^{-6} \mathrm{~m} \mathrm{~s}^{-1}$ at the same temperature. High reaction rate of $\mathrm{MgO}$ with $\mathrm{SO}_{2}$ showed that it had better adsorption capacity than $\mathrm{CuO}$ at an equal residence time.

Bahrami et al. also conducted another research on the $\mathrm{SO}_{2}$ removal in a packed bed reactor by $\mathrm{CuO}$ pellets ${ }^{37}$. They stated that the $\mathrm{CuO}$ breakthrough time at $600{ }^{\circ} \mathrm{C}$ and $\mathrm{SO}_{2}$ concentration of $2500 \mathrm{ppm}$ was about $550 \mathrm{~min}$. The breakthrough time of $\mathrm{MgO}$ curve at $600{ }^{\circ} \mathrm{C}$ and $\mathrm{SO}_{2}$ concentration of 10000 ppm was about $200 \mathrm{~min}$. By applying curve fitting on the experimental results of Bahrami et al., at similar operating conditions, we concluded that the breakthrough times for $\mathrm{MgO}$ and $\mathrm{CuO}$ were approximately the same.

$\mathrm{CaO}$ is the common adsorbent in the throwaway FGD systems. The kinetics study of Moshiri et al. on $\mathrm{CaO}+\mathrm{SO}_{2}$ reaction demonstrated that the rate constant of $\mathrm{CaO}+\mathrm{SO}_{2}$ reaction at $600{ }^{\circ} \mathrm{C}$ was $3.12 \cdot 10^{-7} \mathrm{~m} \mathrm{~s}^{-1}{ }^{44}$. At the same temperature, the reaction rate constant for $\mathrm{MgO}+\mathrm{SO}_{2}$ was $1.11 \cdot 10^{-5}$, which was higher than the corresponding value of $\mathrm{CaO}+\mathrm{SO}_{2}$ reaction.

The packed bed tests of $\mathrm{SO}_{2}+\mathrm{CaO}$ reaction were carried out by Dasgupta et al..$^{25}$ The results of their study indicated that the maximum breakthrough time in $\mathrm{CaO}$ was 60 min obtained at $\mathrm{SO}_{2}$ concentration of 1 vol. \%, temperature of $950{ }^{\circ} \mathrm{C}$ and reactor length of $15 \mathrm{~cm}$. For $\mathrm{MgO}$, the breakthrough time at $\mathrm{SO}_{2}$ concentration of 1 vol.\%, with reactor length of $6 \mathrm{~cm}$, and temperature of $600{ }^{\circ} \mathrm{C}$ was $210 \mathrm{~min}$. This implied higher adsorption capacity of $\mathrm{MgO}$ in comparison with $\mathrm{CaO}$. The better performance of $\mathrm{MgO}$ reduced the number of adsorbent replacement cycles of the packed bed reactor, and as a result, the efficiency of the process would increase and operating costs decrease.

Selvakumar investigated the removal of $\mathrm{SO}_{2}$ by ferric oxide in a packed bed reactor ${ }^{46}$. The results of their study indicated that the breakthrough time of $\mathrm{Fe}_{2} \mathrm{O}_{3}$ at $500{ }^{\circ} \mathrm{C}, \mathrm{SO}_{2}$ concentration of $7.86 \cdot 10^{-3}$ 

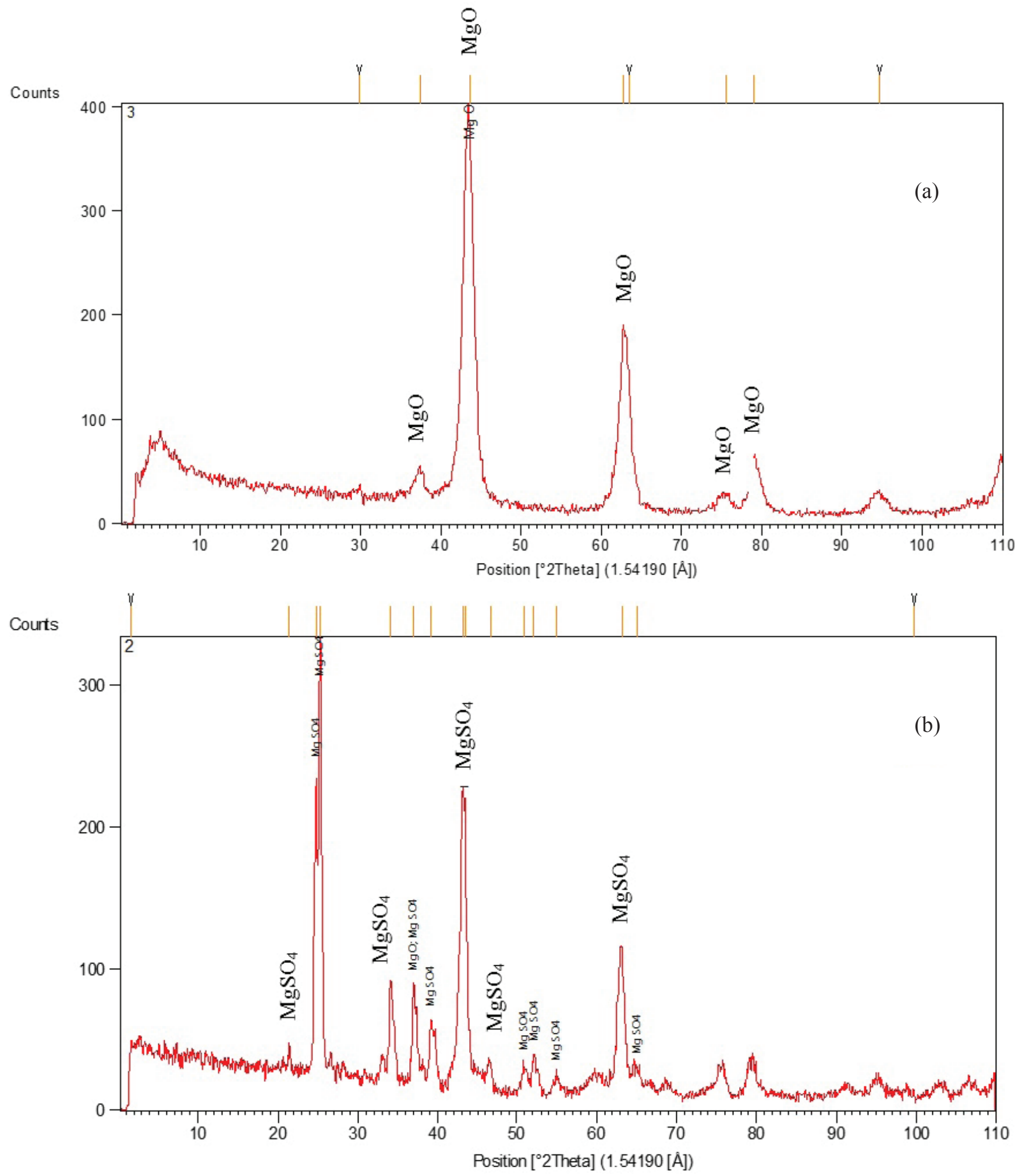

Fig. 7 -XRD analysis of the magnesite sample (a) after calcination process, and (b) after reaction with $\mathrm{SO}_{2}$ in the packed bed reactor 


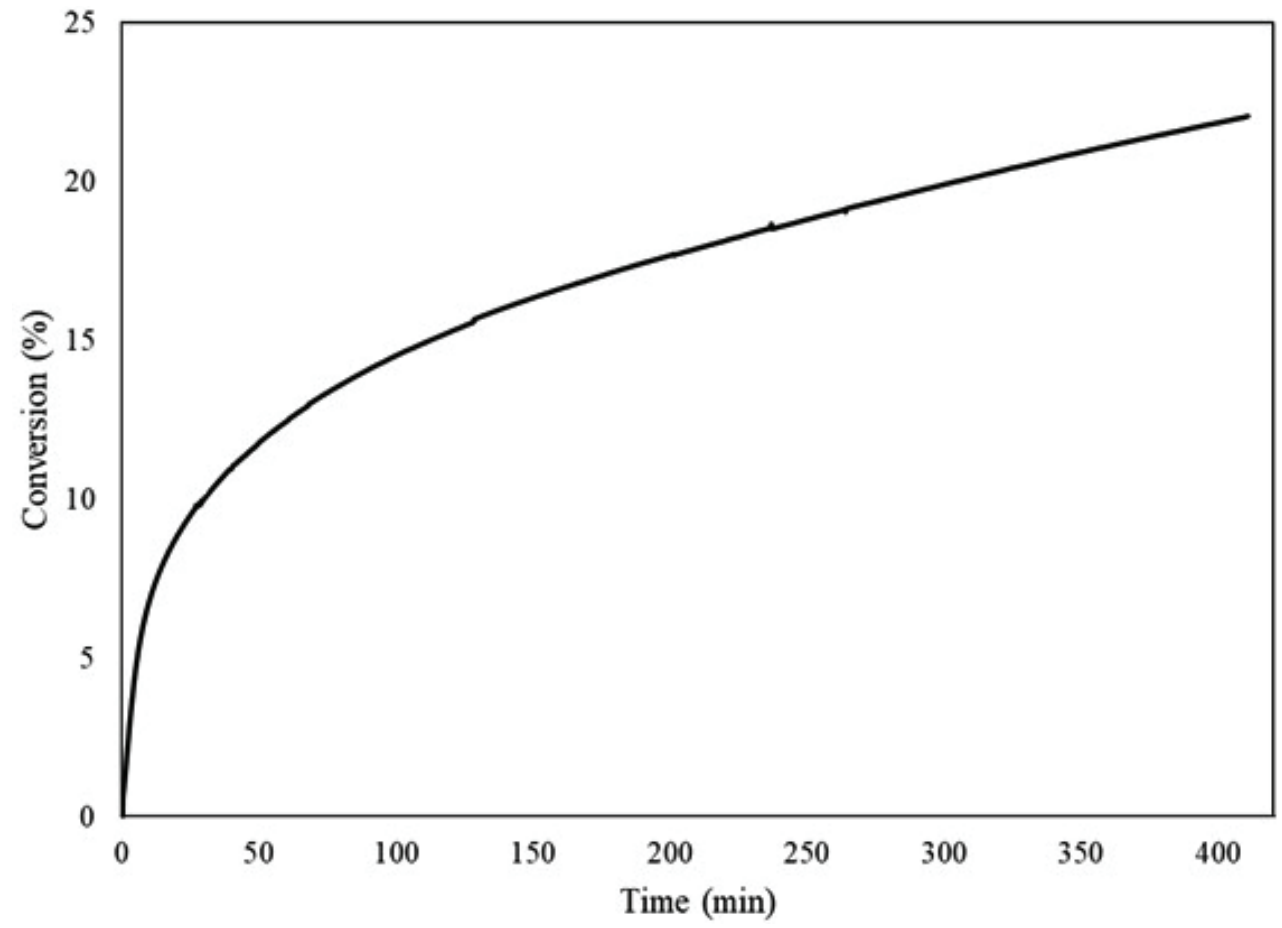

Fig. 8 -Average overall $\mathrm{MgSO}_{4}$ conversion in the packed bed reactor system as the function of reaction time

vol.\% with reactor length of $6 \mathrm{~cm}$ was about 19 min. For $\mathrm{MgO}$, the breakthrough time at $\mathrm{SO}_{2}$ concentration of 1 vol.\% with reactor length of $6 \mathrm{~cm}$ and temperature of $500{ }^{\circ} \mathrm{C}$ was $50 \mathrm{~min}$. The results of comparing breakthrough times show that $\mathrm{MgO}$ adsorption capacity is very much higher than that of $\mathrm{Fe}_{2} \mathrm{O}_{3}$. The comparison of $\mathrm{MgO}$ rate constant with other sorbents is summarized in Table 4.

\section{Optimization results}

In this study, the performance of packed bed reactor for $\mathrm{SO}_{2}$ removal was optimized. The optimization was carried out by NSGA II method and the Pareto-optimal solutions figure was obtained. Pareto-optimal solutions correspond to a situation in which the solutions are not dominated with respect to each other. Moving from a Pareto solution to the next one will result in a certain amount of gain in one objective and a certain amount of sacrifice in the other.

The two target objectives of the optimization were:

- to maximize the packed bed reactor breakthrough time (at $C / C_{0}=0.1$ )

- to minimize the energy consumption in calcination process

Genetic algorithms are commonly used for minimizing the objective function $f(x)$. If a function is to be minimized, $-f(x)$ or $1 / f(x)$ should be considered as the objective functions.
Table 4 - Summary of the comparison between $\mathrm{MgO}$ rate constant with other sorbents

\begin{tabular}{ccc}
\hline Adsorbent & Temperature $\left({ }^{\circ} \mathrm{C}\right)$ & Rate constant $\left(\mathrm{m} \mathrm{s}^{-1}\right)$ \\
\hline $\mathrm{CuO}$ & & $4.37 \cdot 10^{-8}$ \\
$\mathrm{MgO}$ & 500 & $6.01 \cdot 10^{-6}$ \\
$\mathrm{CaO}$ & & $3.12 \cdot 10^{-7}$ \\
$\mathrm{MgO}$ & 600 & $1.11 \cdot 10^{-5}$ \\
\hline
\end{tabular}

The bounds for the multi-objective optimization presented here are:

$500{ }^{\circ} \mathrm{C} \leq$ temperature $\leq 700{ }^{\circ} \mathrm{C}$

1 vol. $\% \leq \mathrm{SO}_{2}$ concentration $\leq 2$ vol. $\%$

$1.67 \cdot 10^{-6} \mathrm{~m}^{3} \mathrm{~s}^{-1}\left(100 \mathrm{cc} \mathrm{min}^{-1}\right) \leq$ zero-air flow rate $\leq$ $3.34 \cdot 10^{-6} \mathrm{~m}^{3} \mathrm{~s}^{-1}\left(200 \mathrm{cc} \mathrm{min}^{-1}\right)$

The multi-objective optimization was carried out based on NSGA II. The NSGA II input parameters are presented in Table 5. The Pareto-optimal solutions after 120 generations are presented in Fig. 9 and Table 6.

The best parameters for maximizing breakthrough lifetime and minimizing the energy consumption are shown in Table 6 . It can be found that improvement in breakthrough time will result in energy consumption increase. All solutions in Pareto-optimal space can be considered as the answer, but the best one has to be selected by the user based on the operating and maintenance costs, experience, 


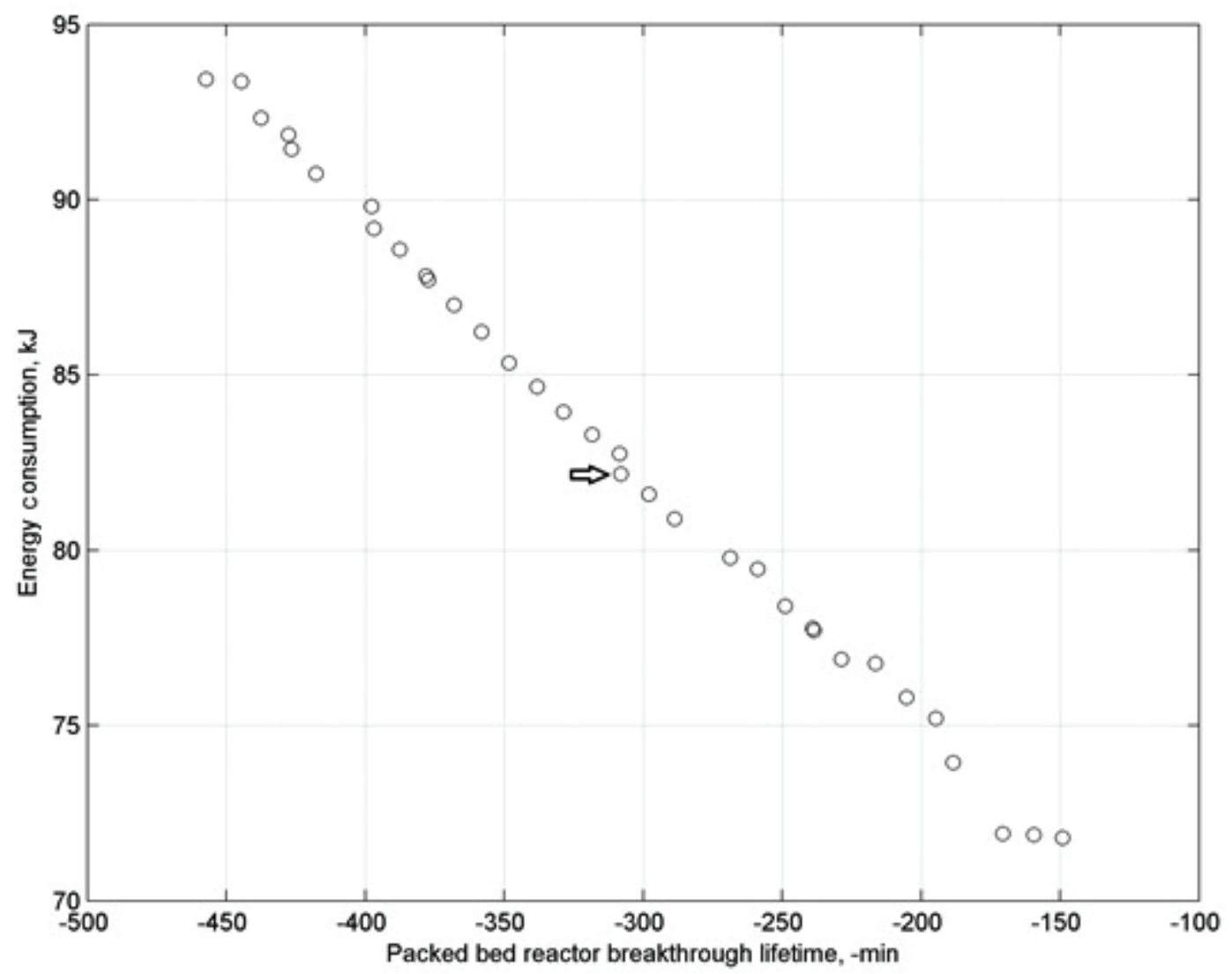

Fig. 9 - Pareto-optimal solutions

and environmental issues. According to the results presented here, the optimum $\mathrm{SO}_{2}$ concentration, zero-air flow rate, and temperature are 1 vol.\%, $1.67 \cdot 10^{-6} \mathrm{~m}^{3} \mathrm{~s}^{-1}\left(100 \mathrm{cc} \mathrm{min}^{-1}\right)$, and $500-643{ }^{\circ} \mathrm{C}$, respectively.

The $\mathrm{SO}_{2}$ concentration and zero-air flow rate were approximately the same in all solutions, and therefore, the appropriate temperature had to be selected. The breakthrough time of chromosomes 12 and 29 were rather similar, but the energy consumption of chromosome 12 was lower than of chromosome 29. Therefore, the situation of chromosome 12 could be considered the appropriate solution. In chromosome 12, the temperature, breakthrough time, and energy consumption were $572.55{ }^{\circ} \mathrm{C}$, $308.52 \mathrm{~min}, 82.76 \mathrm{~kJ}$, respectively. This chromosome is shown by an arrow in Fig. 9.

Table 5 - NSGA II input parameters

\begin{tabular}{cc}
\hline Number of objectives & 2 \\
\hline Number of bounds & 3 \\
Population size & 35 \\
Crossover method & Arithmetic crossover \\
Crossover probability & 0.7 \\
Mutation method & Gauss method \\
Mutation probability & 0.05 \\
\hline
\end{tabular}

\section{Conclusion}

In this study, $\mathrm{SO}_{2}$ adsorption experiments were carried out in a packed bed reactor by $\mathrm{MgO}$ to obtain the breakthrough curves. Furthermore, the effect of important operating parameters including temperature, $\mathrm{SO}_{2}$ concentration, and zero-air flow rate was investigated. Increasing the temperature improved the breakthrough time, but the increase in concentration and flow rate reduced the lifetime. The possibility of simultaneous production of magnesium sulfate, as a useful by product in the process of $\mathrm{SO}_{2}$ removal by $\mathrm{MgO}$, was considered. The XRD analysis verified that $\mathrm{MgSO}_{4}$ is produced as a result of $\mathrm{MgO}+\mathrm{SO}_{2}$ reaction. The experimental results were correlated by applying RPM. The finite element method was used for solving RPM packed bed equations, and the results were compared with the obtained experimental data. There was a satisfactory agreement between the RPM values predicted by the model and the experimental breakthrough curve data.

The comparison of $\mathrm{MgO}$ performance with other sorbents for $\mathrm{SO}_{2}$ removal was also carried out in this research. The reaction rate and the breakthrough time of $\mathrm{MgO}$ were mostly higher than other sorbents. As a result, the application of $\mathrm{MgO}$ in dry FGD systems could improve the efficiency of these units. 
Table 6 - Pareto-optimal solutions after 120 generations

\begin{tabular}{|c|c|c|c|c|c|}
\hline No. & $\begin{array}{c}\text { Temperature } \\
\left({ }^{\circ} \mathrm{C}\right)\end{array}$ & $\begin{array}{c}\mathrm{SO}_{2} \text { concentration } \\
\text { (vol.\%) }\end{array}$ & $\begin{array}{l}\text { Zero-air flow rate } \\
\qquad\left(\mathrm{cc} \mathrm{min}^{-1}\right)\end{array}$ & $\begin{array}{l}\text { Breakthrough time } \\
\text { (min) }\end{array}$ & $\begin{array}{l}\text { Energy consumption } \\
(\mathrm{kJ})\end{array}$ \\
\hline 1 & 500 & 1.20 & 1.05 & 149.12 & 71.79 \\
\hline 2 & 611.01 & 1.00 & 1.00 & 387.54 & 88.57 \\
\hline 3 & 643.22 & 1.00 & 1.00 & 457.34 & 93.44 \\
\hline 4 & 606.10 & 1.00 & 1.00 & 378.12 & 87.83 \\
\hline 5 & 522.53 & 1.01 & 1.00 & 194.81 & 75.20 \\
\hline 6 & 543.72 & 1.00 & 1.00 & 248.85 & 78.40 \\
\hline 7 & 580.37 & 1.00 & 1.00 & 328.72 & 83.94 \\
\hline 8 & 568.65 & 1.00 & 1.00 & 308.05 & 82.17 \\
\hline 9 & 595.52 & 1.00 & 1.00 & 358.22 & 86.23 \\
\hline 10 & 605.34 & 1.00 & 1.00 & 377.41 & 87.71 \\
\hline 11 & 539.53 & 1.00 & 1.00 & 238.97 & 77.77 \\
\hline 12 & 572.55 & 1.00 & 1.00 & 308.52 & 82.76 \\
\hline 13 & 635.92 & 1.00 & 1.00 & 437.57 & 92.33 \\
\hline 14 & 630.01 & 1.00 & 1.00 & 426.56 & 91.44 \\
\hline 15 & 514.20 & 1.00 & 1.00 & 188.43 & 73.94 \\
\hline 16 & 614.96 & 1.00 & 1.00 & 396.89 & 89.17 \\
\hline 17 & 632.73 & 1.00 & 1.00 & 427.54 & 91.85 \\
\hline 18 & 500 & 1.20 & 1.05 & 149.12 & 71.79 \\
\hline 19 & 625.36 & 1.00 & 1.00 & 417.74 & 90.74 \\
\hline 20 & 539.09 & 1.00 & 1.00 & 238.69 & 77.70 \\
\hline 21 & 585.10 & 1.00 & 1.00 & 338.07 & 84.66 \\
\hline 22 & 619.15 & 1.00 & 1.00 & 397.69 & 89.80 \\
\hline 23 & 533.71 & 1.00 & 1.00 & 228.65 & 76.89 \\
\hline 24 & 500.74 & 1.09 & 1.01 & 170.73 & 71.91 \\
\hline 25 & 526.45 & 1.01 & 1.01 & 205.29 & 75.79 \\
\hline 26 & 642.81 & 1.00 & 1.00 & 444.67 & 93.38 \\
\hline 27 & 560.24 & 1.00 & 1.00 & 288.71 & 80.90 \\
\hline 28 & 589.66 & 1.00 & 1.00 & 348.24 & 85.34 \\
\hline 29 & 576.06 & 1.00 & 1.00 & 318.35 & 83.29 \\
\hline 30 & 532.92 & 1.01 & 1.00 & 216.52 & 76.77 \\
\hline 31 & 550.70 & 1.00 & 1.00 & 258.74 & 79.46 \\
\hline 32 & 552.84 & 1.00 & 1.00 & 268.81 & 79.78 \\
\hline 33 & 600.63 & 1.00 & 1.00 & 368.05 & 87.01 \\
\hline 34 & 564.88 & 1.00 & 1.00 & 298.04 & 81.60 \\
\hline 35 & 500.55 & 1.16 & 1.02 & 159.509 & 71.88 \\
\hline
\end{tabular}


Finally, NSGA II was employed as a technique for multi-objective optimization to determine the best operating parameters for the removal of $\mathrm{SO}_{2}$ by magnesium oxide in the packed bed reactor. The optimization goals were to maximize reactor breakthrough time and minimize its energy consumption. The bounds on temperature, $\mathrm{SO}_{2}$ concentration, and zero-air flow rate were used. The Pareto-optimal solutions were obtained and the optimal operating parameters were determined. The optimum $\mathrm{SO}_{2}$ concentration, zero-air flow rate, and temperature are $1 \mathrm{vol} . \%, 1.67 \cdot 10^{-6} \mathrm{~m}^{3} \mathrm{~s}^{-1}\left(100 \mathrm{cc} \mathrm{min}^{-1}\right)$, and 500 $643{ }^{\circ} \mathrm{C}$, respectively.

\section{List of symbols}

$a=C_{A} / C_{A b}-$ Dimensionless gas concentration

$b=C_{B} / C_{B 0}-$ Dimensionless solid concentration

$C_{A} \quad-$ Gas concentration in the pellet, $\mathrm{kmol} \mathrm{m}^{-3}$

$C_{A b} \quad-$ Bulk gas concentration, $\mathrm{kmol} \mathrm{m}^{-3}$

$C_{B} \quad-$ Solid reactant concentration, $\mathrm{kmol} \mathrm{m}^{-3}$

$C_{B 0} \quad-$ Initial solid reactant concentration, $\mathrm{kmol} \mathrm{m}^{-3}$

$D_{\mathrm{AK}} \quad-$ Knudsen diffusivity, $\mathrm{m}^{2} \mathrm{~s}^{-1}$

$D_{\text {AM }} \quad-$ Molecular diffusivity of gas A in the pellet, $\mathrm{m}^{2} \mathrm{~s}^{-1}$

$D_{e} \quad-$ Effective diffusivity of gas A in the pellet, $\mathrm{m}^{2} \mathrm{~s}^{-1}$

$D_{e 0} \quad-$ Initial effective diffusivity of gas $\mathrm{A}$ in pores, $\mathrm{m}^{2} \mathrm{~s}^{-1}$

$D_{\mathrm{p}} \quad-$ Diffusivity of gas A in product layer, $\mathrm{m}^{2} \mathrm{~s}^{-1}$

$k_{\mathrm{m}} \quad-$ External mass-transfer coefficient, $\mathrm{m} \mathrm{s}^{-1}$

$k_{\mathrm{s}} \quad-$ Surface rate constant, $\mathrm{m} \mathrm{s}^{-1}$

$L \quad-$ Thickness of the pellet, $\mathrm{m}$

$L_{0} \quad$ - Pore length per unit volume, $\mathrm{m}^{-2}$

$M_{\mathrm{B}} \quad-$ Molecular weight of solid reactant, $\mathrm{kg} \mathrm{kmol}{ }^{-1}$

$M_{\mathrm{D}} \quad-$ Molecular weight of solid product, $\mathrm{kg} \mathrm{\textrm {kmol } ^ { - }}$

- Pore radius, $\mathrm{m}$

- Each point position in the pellet, $\mathrm{m}$

- Average pore radius of the pellet, $m$

- Spherical pellet radius, $\mathrm{m}$

$S_{0} \quad-$ Reaction surface area per unit volume, $\mathrm{m}^{-1}$

$S h=\frac{k_{m} L}{2 D_{A M}}-$ Sherwood number for external mass transfer

$t \quad{ }^{A M} \quad-$ Time, s

$V_{p} \quad-$ Total pore volume, $\mathrm{m}^{3} \mathrm{~kg}^{-1}$

$x \quad-$ Axial distance from beginning of bed, $\mathrm{m}$

$y=2 z / L \quad-$ Dimensionless position in the pellet

$z \quad-$ Distance from the center of the pellet, $\mathrm{m}$

Z - Ratio of molar volume of solid product to solid reactant

$m_{a d} \quad-$ Mass of the adsorbent, $\mathrm{kg}$
$C_{p, a d} \quad-$ Specific heat of the adsorbent, $\mathrm{J} \mathrm{K}^{-1} \mathrm{~kg}^{-1}$

$T_{\text {cal }} \quad-$ Calcination temperature, $\mathrm{K}$

$T_{0} \quad-$ Environmental temperature, $\mathrm{K}$

$m_{r} \quad-$ Mass of the reactor, $\mathrm{kg}$

$C_{p, r} \quad-$ Specific heat of the reactor, $\mathrm{J} \mathrm{K}^{-1} \mathrm{~kg}^{-1}$

$h \quad-$ Convection coefficient, $\mathrm{W} \mathrm{m} \mathrm{m}^{-2} \mathrm{~K}^{-1}$

$A_{r} \quad-$ Surface area of the reactor, $\mathrm{m}^{2}$

$t_{\text {cal }} \quad-$ Calcination time, $\mathrm{s}$

Q - Required heat, $\mathrm{J}$

$v_{0}(r) \quad-$ Pore volume distribution function, $\mathrm{m}^{2} \mathrm{~kg}^{-1}$

$X(\theta) \quad-$ Conversion of solid at each time

$\beta=2 k_{s}\left(1-\varepsilon_{0}\right) /\left(v_{B} D_{p} S_{0}\right)$ - Product layer resistance

$\varepsilon \quad-$ Pellet porosity

$\varepsilon_{0} \quad-$ Initial pellet porosity

$\delta=D_{e} / D_{e 0}-$ Variation ratio of the pore diffusion

$\theta=k_{s} S_{0} C_{A b} t /\left[C_{B 0}\left(1-\varepsilon_{0}\right]=t / \tau-\right.$ Dimensionless time

$v_{B} \quad-$ Stoichiometric coefficient of the solid reactant

$v_{D} \quad-$ Stoichiometric coefficient of the solid product

$\rho_{B} \quad-$ True density of the solid reactant, $\mathrm{kg} \mathrm{m}^{-3}$

$\rho_{D} \quad-$ True density of the solid product, $\mathrm{kg} \mathrm{m}^{-3}$

$\phi=(L / 2)\left(k_{s} S_{0} C_{A b}^{n-1} / v_{B} D_{e 0}\right)^{1 / 2}-$ Thiele modulus for the pellet

$\psi \quad-$ Random pore model main parameter

$\zeta \quad-$ Dimensionless reactor length

\section{References}

1. Wondyfraw, M., Mechanisms and effects of acid rain on environment, J. Earth Sci. Clim. Chang. 5 (2014) 240.

2. Maheswari, C., Krishnamurthy, K., Parameshwaran, R., Modeling and experimental analysis of packed column for $\mathrm{SO}_{2}$ emission control process, Atmos. Pollut. Res. 5 (2014) 464 . doi: https://doi.org/10.5094/APR.2014.054

3. Kirk, R. E., Othmer, D. F., Kroschwitz, J. I., Howe-Grant, $M$., Encyclopedia of Chemical Technology, 1991.

4. Stanislaus, A., Marafi, A., Rana, M. S., Recent advances in the science and technology of ultra low sulfur diesel (ULSD) production, Catal. Today 153 (2010) 1. doi: https://doi.org/https://doi.org/10.1016/j.cattod.2010.05.011

5. Bakhshi Ani, A., Ale Ebrahim, H., Azarhoosh, M. J., Simulation and multi-objective optimization of a trickle-bed reactor for diesel hydrotreating by a heterogeneous model using non-dominated sorting genetic algorithm II, Energy \& Fuels 29 (2015) 3041 doi: https://doi.org/10.1021/acs.energyfuels.5b00467

6. Fooladi Toosi, A., Samie, M. S., Dashti, A., Atarian Shandiz, M., Simulation of a non-isothermal industrial hydrotreating reactor using simulink, Energy \& Fuels 28 (2014) 4828.

doi: https://doi.org/10.1021/ef500701q

7. Organo-Silicon Compounds. In Industrial Inorganic Chemistry, pp 213-293.

doi: https://doi.org/10.1002/9783527613328.ch03 
8. Yoko, K., Magnesium Sulfate Chemical and Technical Assessment, Food and Agriculture Organization of the United Nations (FAO), 2007.

9. Jae, L. S., Jun, H. K., Jung, S. Y., Lee, T. J., Ryu, C. K., Kim, J. C., Regenerable MgO-Based SOx removal sorbents promoted with cerium and iron oxide in RFCC, Ind. Eng. Chem. Res. 44 (2005) 9973. doi: https://doi.org/10.1021/ie050607u10.1021/ie050607u

10. Zhang, Q., Tao, Q., He, H., Liu, H., Komarneni, S., An efficient $\mathrm{SO}_{2}$-adsorbent from calcination of natural magnesite, Ceram. Int. 43 (2017) 12557. doi: https://doi.org/https://doi.org/10.1016/j.ceramint.2017.06.130

11. Przepiórski, J., Czyżewski, A., Kapica, J., Moszyński, D., Grzmil, B., Tryba, B., Mozia, S., Morawski, A.W., Low temperature removal of $\mathrm{SO}_{2}$ traces from air by $\mathrm{MgO}$-loaded porous carbons, Chem. Eng. J. 191 (2012) 147. doi: https://doi.org/https://doi.org/10.1016/j.cej.2012.02.087

12. del Valle-Zermeño, R., Formosa, J., Aparicio, J. A., Chimenos, J. M., Reutilization of low-grade magnesium oxides for flue gas desulfurization during calcination of natural magnesite: A closed-loop process, Chem. Eng. J. 254 (2014) 63 doi: https://doi.org/10.1016/j.cej.2014.05.089

13. Lee, S. J., Jung, S. Y., Lee, S. C., Jun, H. K., Ryu, C. K., Kim, J. C., $\mathrm{SO}_{2}$ removal and regeneration of MgO-based sorbents promoted with titanium oxide, Ind. Eng. Chem. Res. 48 (2009) 2691. doi: https://doi.org/10.1021/ie801081u

14. Magnabosco, L. M., Chapter 16 Principles of the SOx Reduction Technology in Fluid Catalytic Cracking Units (FCCUs). In Studies in Surface Science and Catalysis, Ocelli, M. L., Ed., Elsevier, 2007, pp 253-305. doi: https://doi.org/https://doi.org/10.1016/S0167-2991(07) 80199-6

15. $L i, X$., Selection of Typical Wet Desulfurization System and Economic Analysis of Variable Load Operation for Industrial Coal-Fired Boilers. IOP Conf. Ser.: Mater. Sci. Eng. 721 012014. 2020.

16. Yi, H., Ma, C., Tang, X., Zhao, S., Yang, K., Sani, Z., Song, L., Zhang, X., Han, W., Synthesis of $\mathrm{MgO} @ \mathrm{CeO}_{2}-\mathrm{MnOx}$ Core shell structural adsorbent and its application in reducing the competitive adsorption of $\mathrm{SO}_{2}$ and $\mathrm{NOx}$ in coalfired flue gas, Chem. Eng. J. 372 (2019) 129. doi: https://doi.org/https://doi.org/10.1016/j.cej.2019.04.120

17. Litao, Q. U., Evaluation of Ultralow Emission Performance of Magnesium Oxide ( $\mathrm{MgO}$ ) Wet Flue Gas Desulfurization Unit for Coal-Fired Units. IOP Conf. Ser.: Earth Environ. Sci. 267 062045. 2019.

18. Zou, Y., Liu, X., Zhu, T., Tian, M., Cai, M., Zhao, Z., Wu, $H$., Simultaneous removal of $\mathrm{NOx}$ and $\mathrm{SO}_{2}$ by $\mathrm{MgO}$ combined with $\mathrm{O}_{3}$ oxidation: The influencing factors and $\mathrm{O}_{3}$ consumption distributions, ACS Omega 4 (2019) 21091. doi: https://doi.org/10.1021/acsomega.9b02502

19. Wang, G., Ren, S., Zhang, J., Ning, X., Liang, W., Zhang, $N$., Wang, C., Influence mechanism of alkali metals on $\mathrm{CO}_{2}$ gasification properties of metallurgical coke, Chem. Eng. J. 387 (2020). doi: https://doi.org/10.1016/j.cej.2020.124093

20. Zhao, M., Zou, C., The effect of particle size on removal of $\mathrm{SO}_{2}$ from flue gas by $\mathrm{MgO}$ absorbents, Powder Technol. 377 (2021) 506. doi: https://doi.org/https://doi.org/10.1016/j.powtec.2020.08.092

21. Osafi, M. R., Bakhshi Ani, A., Kalbasi, M., Numerical modeling of solid acid fuel cell performance with $\mathrm{CsH}_{2} \mathrm{PO}_{4}$ AAM (anodic alumina membrane) composite electrolyte, Int. J. Heat Mass Transf. 129 (2019) 1086. doi: https://doi.org/https://doi.org/10.1016/j.ijheatmasstransfer. 2018.10.049
22. Bahrami, R., Ebrahim, H. A., Halladj, R., Afshar, A., A comprehensive kinetic study of the $\mathrm{SO}_{2}$ removal reaction by pure $\mathrm{CuO}$ with the random pore model, Prog. React. Kinet. Mech. 41 (2016) 385

doi: https://doi.org/10.3184\%2F146867816X14716171449503

23. Moshiri, H., Nasernejad, B., Ale Ebrahim, H., Taheri, M., Solution of coupled partial differential equations of a packed bed reactor for $\mathrm{SO}_{2}$ removal by lime using the finite element method, RSC Adv. 5 (2015) 18116. doi: https://doi.org/10.1039/C4RA16463F

24. Betancur, M., Natalia Arenas, C., Daniel Martínez, J., Victoria Navarro, M., Murillo, $R ., \mathrm{CO}_{2}$ gasification of char derived from waste tire pyrolysis: Kinetic models comparison, Fuel 273 (2020) 117745. doi: https://doi.org/10.1016/j.fuel.2020.117745

25. López, J. M., Grasa, G., Murillo, R., Evaluation of the effect of inert support on the carbonation reaction of synthetic CaO-based $\mathrm{CO}_{2}$ sorbents, Chem. Eng. J. 350 (2018) 559. doi: https://doi.org/10.1016/j.cej.2018.05.014

26. Montagnaro, F., Salatino, P., Scala, F., The influence of temperature on limestone sulfation and attrition under fluidized bed combustion conditions, Sixth Mediterr. Combust. Symp. 34 (2010) 352. doi: https://doi.org/10.1016/j.expthermflusci.2009.10.013

27. Yu, Q., Deng, Y., Wang, F., Feng, Y., Yang, B., Xu, B., Liu, $D$., Comparison of desulfurization kinetics of copper oxide sorbent, J. Cent. South Univ. 22 (2015) 2902. doi: https://doi.org/10.1007/s11771-015-2824-z

28. Nouri, S. M. M., Ebrahim, H. A., Nasernejad, B., Afsharebrahimi, $A$., Investigation of $\mathrm{CO}_{2}$ reaction with $\mathrm{CaO}$ and an acid washed lime in a packed-bed reactor, Chem. Eng. Commun. 203 (2016) 1. doi: https://doi.org/10.1080/00986445.2014.938805

29. Bakhshi Ani, A., Ale Ebrahim, H., Comprehensive kinetic study of sulfur dioxide removal by magnesium oxide using TG, J. Therm. Anal. Calorim. (2021). doi: https://doi.org/10.1007/s10973-021-10597-6

30. Ani, A. B., Ebrahim, H. A., Theoretical and experimental investigation on improvement of magnesium oxide sorbent by acetic acid washing for enhancing flue gas desulfurization performance, Chem. Pap. (2020). doi: https://doi.org/10.1007/s11696-020-01093-6

31. Morales-Rodriguez, R., Meyer, A. S., Gernaey, K. V., Sin, $G$., A framework for model-based optimization of bioprocesses under uncertainty: Identifying critical parameters and operating variables. In computer aided chemical engineering, Pistikopoulos, E. N., Georgiadis, M. C., Kokossis, A. C., Eds., Elsevier, 2011, pp 1455-1459. doi: https://doi.org/10.1016/B978-0-444-54298-4.50070-2

32. Kussi, J., Perne, R., Schuppert, A., Process software in the chemical industry - the challenge of complexity. In computer aided chemical Engineering, Grievink, J., van Schijndel, J., Eds., Elsevier, 2002, pp 23-30. doi: https://doi.org/https://doi.org/10.1016/S1570-7946(02)80036-0

33. Wu, L., Wang, Y., Zheng, L., Han, X., Hong, F., Multi-objective operational optimization of a hydrotreating process based on hydrogenation reaction kinetics, Ind. Eng. Chem. Res. 57 (2018) 15785. doi: https://doi.org/10.1021/acs.iecr.8b03379

34. Zhou, B., Wang, T., Li, C., Fu, J., Zhang, Z., Song, Z., Ma, $C$., Multi-objective optimization of the preparation parameters of the powdered activated coke for $\mathrm{SO}_{2}$ adsorption using response surface methodology, J. Anal. Appl. Pyrolysis $146(2020) 104776$ doi: https://doi.org/https://doi.org/10.1016/j.jaap.2020.104776 
35. Bayón, L., Grau, J. M., Ruiz, M. M., Suárez, P. M., Optimization of $\mathrm{SO}_{2}$ and $\mathrm{NO}_{\mathrm{x}}$ emissions in thermal plants, J. Math. Chem. 40 (2006) 29. doi: https://doi.org/10.1007/s10910-006-9127-4

36. Liu, J., Tomassone, M. S., Kuang, X., Zhou, S., Operation parameters and design optimization based on CFD simulations on a novel spray dispersion desulfurization tower, Fuel Process. Technol. 209 (2020) 106514 doi: https://doi.org/10.1016/j.fuproc.2020.106514

37. Bahrami, R., Ale Ebrahim, H., Halladj, R., Ale Ebrahim, M. $A$., Applying the random pore model in a packed bed reactor for the regenerative $\mathrm{SO}_{2}$ removal reaction by $\mathrm{CuO}$, Ind. Eng. Chem. Res. 53 (2014) 16285. doi: https://doi.org/10.1021/ie502581n10.1021/ie502581n

38. Bhatia, S. K., Perlmutter, D. D., A random pore model for fluid-folid reactions: II. diffusion and transport effects, AIChE J. 27 (1981) 247. doi: https://doi.org/10.1002/aic.690270211

39. Ale Ebrahim, H., Application of random-pore model to $\mathrm{SO}_{2}$ capture by lime, Ind. Eng. Chem. Res. 49 (2010) 117. doi: https://doi.org/10.1021/ie901077b

40. Saeed, G., 16 - Structural Optimization for Frequency Constraints. In Metaheuristic Applications in Structures and Infrastructures, Gandomi, A. H., Yang, X.-S., Talatahari, S., Alavi, A. H., Eds., Elsevier: Oxford, 2013, pp 389-417. doi: https://doi.org/10.1016/B978-0-12-398364-0.00016-4
41. Roetzel, W., Luo, X., Chen, D., Chapter 6 - Optimal Design of Heat Exchanger Networks. In Design and Operation of Heat Exchangers and their Networks, Roetzel, W., Luo, X., Chen, D., Eds., Academic Press, 2020, pp 231-317. doi: https://doi.org/10.1016/B978-0-12-817894-2.00006-6

42. Li, M., Liu, S., Zhang, L., Wang, H., Meng, F., Bai, L., Non-dominated sorting genetic algorithms-II based on multi-objective optimization model in the water distribution system, Procedia Eng. 37 (2012) 309 doi: https://doi.org/10.1016/j.proeng.2012.04.245

43. Levenspiel, O., Chemical Reaction Engineering, Ind. Eng. Chem. Res. 38 (1999) 4140. doi: https://doi.org/10.1021/ie990488g

44. Moshiri, H., Nasernejad, B., Ebrahim, H. A., Taheri, M., A comprehensive kinetic study of the reaction of $\mathrm{SO}_{2}$ with $\mathrm{CaO}$ by the random pore model, Chem. Eng. Technol. 37 (2014) 2037. doi: https://doi.org/10.1002/ceat.201400285

45. Dasgupta, K., Rai, K., Verma, N., Breakthrough and sulfate conversion analysis during removal of sulfur dioxide by calcium oxide sorbents, Can. J. Chem. Eng. 81 (2003) 53. doi: https://doi.org/10.1002/cjce.5450810106

46. Selvakumar, J. A., Thirumalaikumar, R., Removal of sulphur dioxide by ferric oxide in packed bed and analyze break through curves and mass transfer zone, Int. J. Eng. Res. Technol. 01 (2012) 